\title{
Changes in the shear strength and micro-penetration hardness of a buried surface-hoar layer
}

\author{
Karl W. BIRKELAND, ${ }^{1,2}$ Kalle KRONHOLM, ${ }^{3}$ Martin SCHNEEBELI, ${ }^{3}$ \\ Christine PIELMEIER ${ }^{3}$ \\ ${ }^{1}$ USDA Forest Service National Avalanche Center, P.O. Box 130, Bozeman, MT 59771, U.S.A. \\ E-mail: kbirkeland@fs.fed.us \\ ${ }^{2}$ Department of Earth Sciences, Montana State University, Bozeman, MT 59717, U.S.A. \\ ${ }^{3}$ WSL Swiss Federal Institute for Snow and Avalanche Research SLF, Flüelastrasse 11, CH-7260 Davos-Dorf, Switzerland
}

\begin{abstract}
We investigated a buried surface-hoar layer using the Snow MicroPen (SMP), an instrument designed to measure detailed snow pack profiles. We collected data from two adjacent parts of a slope 6 days apart. In addition, one manual snowpack profile was sampled each day, as well as 50 quantified loaded column tests (QLCTs) which provided an index of shear strength. For the SMP data, a $900 \mathrm{~m}^{2}$ area was sampled on both days in a grid with points $3 \mathrm{~m}$ apart, with some sub-areas of more closely spaced measurements. We collected 86 SMP profiles on the first day and 129 on the second day. Our analyses involved manually locating layer boundaries and calculating statistics for the force signal through the surface-hoar layer. The shear strength index increased by $40 \%$ between the two sampling days, but the SMP data show no statistical difference in layer thickness, and the mean, minimum, median, and a variety of percentile measures of the SMP force signal through the layer also do not change. Interestingly, the maximum hardness, and the variance and coefficient of variation of the SMP signal, increased. Since the small SMP tip might only break one or a couple of bonds as it passes through the weak layer, we interpret these changes as being indicative of increasing bond strength. Though we cannot specifically tie the increasing maximum hardness of the SMP signal to our QLCT results, our work suggests that the maximum SMP signal within buried surfacehoar layers may be useful for tracking increases in the shear strength of those layers.
\end{abstract}

\section{INTRODUCTION}

Though several types of crystals form weak layers in the snowpack, surface-hoar layers are particularly persistent and dangerous. Surface hoar forms in all snow climates and, once buried, sometimes persists for months. Even experienced avalanche professionals find judging the stability of surface hoar layers to be difficult; in Canada, surfacehoar layers are responsible for more avalanches involving professionals than any other weak layer (Jamieson, 1995, p. 18). An improved knowledge of the strength and hardness changes in surface hoar through time will improve our understanding of this critical weak layer.

A number of past studies investigated surface hoar. Lang and others (1984) and Hachikubo and Akitaya (1997) documented the necessary conditions for surface-hoar formation. Extensive field campaigns in Canada demonstrated changes in surface-hoar layers through time, their persistence and their contribution to avalanche formation (e.g. Jamieson, 1995; Jamieson and Johnston, 1999; Jamieson and Schweizer, 2000; Chalmers and Jamieson, 2001, 2003). The best field indication for surface-hoar strengthening, other than direct strength measurements, is the thinning of the surface-hoar layer and a decrease in the maximum-size crystals in the layer (Jamieson and Schweizer, 2000). Less research has focused on microstructure, though Davis and others $(1997,1998)$ used thin sections to carefully analyze changes in surface hoar through time. Jamieson and Schweizer (2000) proposed a conceptual model of changes in surface-hoar microstructure over time that encourages strengthening. In essence, in their model strengthening occurs due to weak-layer thinning, which allows the surface-hoar crystals to penetrate the layers above and below and thereby strengthens the contacts with those layers.

This paper builds on previous research by analyzing a surface-hoar layer on two different days on two parts of a single slope with a new instrument. We made detailed measurements of penetration resistance with the Snow MicroPen (SMP; Schneebeli and others, 1999), and supplemented those data with quantified loaded column tests (QLCTs; Landry and others, 2001) which allowed the calculation of a shear strength index. The primary purpose of our research is to investigate changes in the penetration resistance, as measured by the SMP, of a buried surface-hoar layer.

\section{FIELD AREA AND METHODS}

\section{Field area and weak-layer formation}

For sampling, we utilized a slope in the Lionhead area, located about $15 \mathrm{~km}$ west of West Yellowstone, Montana, U.S.A. (approximately $44^{\circ} 45^{\prime} \mathrm{N}, 111^{\circ} 15^{\prime} \mathrm{W}$ ). The slope is northeast-facing, generally planar, and protected from 

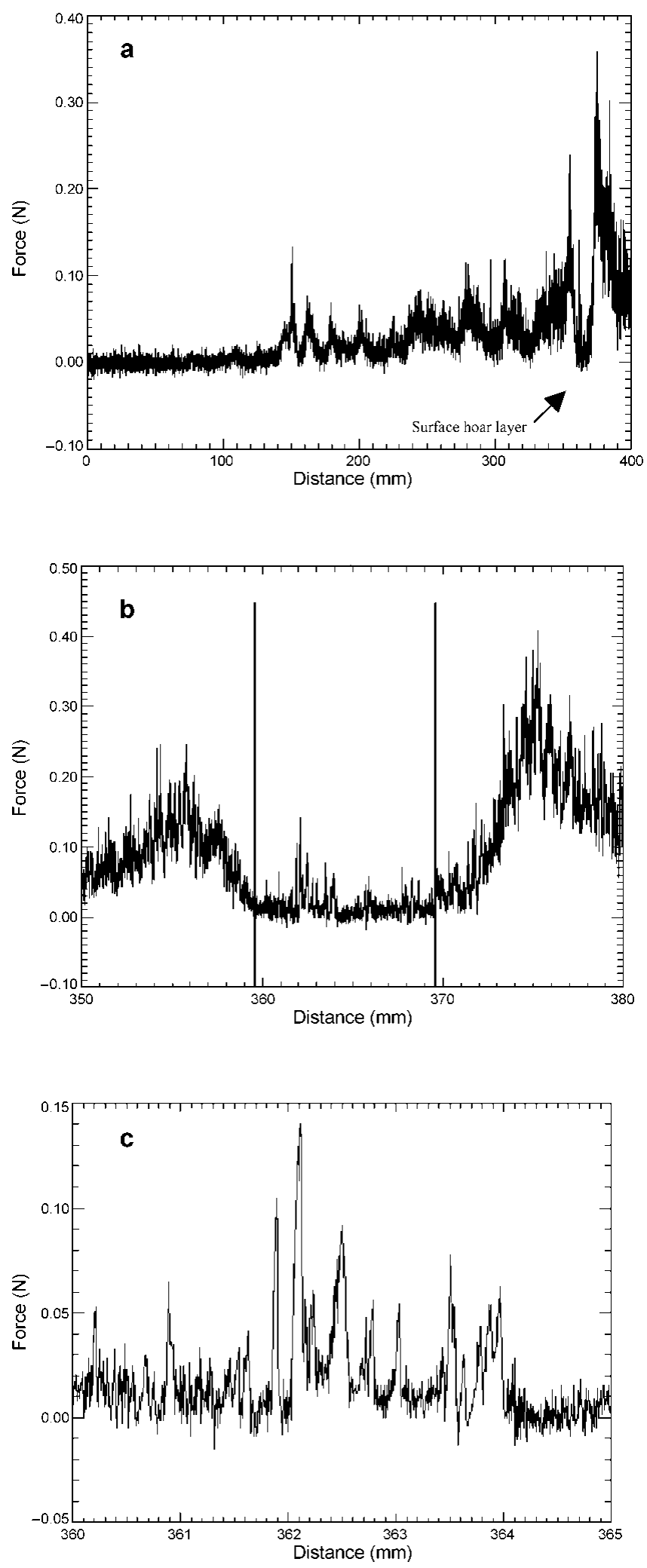

Fig. 1. A SMP profile from 15 January 2002 showing (a) the location of the surface-hoar layer, ( $b$ ) our manual delineation of the exact boundaries of the surface-hoar layer for our analyses, and (c) a detailed view of some of the SMP signal within the surface-hoar layer.

ridge-top winds, and the areas sampled have slope angles of 25-28 $8^{\circ}$. A layer of $15-20 \mathrm{~mm}$ surface hoar formed on the slope from 21 to 26 December 2001. This layer was buried on 27 December, and we sampled areas on the slope on 9 and 15 January. No remote instrumentation is available at this site, so we can only roughly reconstruct the evolution of the weak layer and slab. After deposition, a thin slab of snow $(28 \mathrm{~cm})$ buried the surface hoar before the 9 January sampling day. Between the 9 th and the 15 th little new snow fell and the measured shear stress on the weak layer - calculated from the slope angle, slab density and slab thickness - increased from 148 to $170 \mathrm{~N} \mathrm{~m}^{-2}$ between the two days. It is important to note that we sampled two different areas on the same slope. Though the slope appeared to be relatively uniform, we cannot be sure that the initial conditions for each of our sampling areas were exactly the same.

\section{Data collection}

We used the QLCT to measure changes in an index of shear strength of the targeted surface-hoar layer. Landry and others (2001) provide a detailed description of the method and the calculation of the index. The SMP provided the hardness measurements. The SMP is a motor-driven, constant-speed micropenetrometer which generates high-resolution data, sampling 250 measurements of hardness (penetration resistance) per mm. Previous work with the SMP demonstrates its effectiveness for discriminating between different crystal types and different layers (Johnson and Schneebeli, 1999; Schneebeli, 1999; Schneebeli and others, 1999; Pielmeier and others, 2001; Pielmeier and Schneebeli, in press), though none of this research has investigated the characteristics of a particular weak layer.

We sampled two $900 \mathrm{~m}^{2}$ areas ( 30 by $30 \mathrm{~m}$ ) located within $50 \mathrm{~m}$ of each other. On each day, we collected the following: (1) a manual snow profile (Colbeck and others, 1990); (2) 50 QLCTs (Landry and others, 2001), which provided a shear strength index and shear stress data; and (3) a number of SMP profiles. Within each $900 \mathrm{~m}^{2}$ sampling area there were five snow pits, and we conducted ten QLCTs in each pit (for a diagram of the pit layout, see Landry and others, 2002). We took our SMP measurements in a grid with $3 \mathrm{~m}$ spacing throughout the area, being careful not to disturb the QLCT snow pits. We conducted a finer grid, with $1 \mathrm{~m}$ spacing, around the central QLCT pit in the middle of the sampling area, and adjacent to that area we conducted a small grid with $0.5 \mathrm{~m}$ spacing. A total of $86 \mathrm{SMP}$ profiles were collected on the first day and 129 on the second day; equipment difficulties on the first day prevented the collection of additional data, so no $0.5 \mathrm{~m}$ grid was sampled on that day.

\section{Data analysis}

For the QLCT data, we pooled the measurements of the shear strength index for each day and tested the data for normality using the Lilliefors test (Statsoft, 1994). Both days had normally distributed data $(p>0.05)$, so we used a standard $t$ test to test for differences in the index of shear strength between the two days.

For the SMP data, no adequate algorithms currently exist for layer identification. Therefore, we manually located the surface-hoar layer boundaries in each SMP profile (Fig. 1). Boundaries in the SMP signal are not discrete like those often plotted in manual snow-pit profiles. Instead, there is a gradation from layer to layer that is caused both by an actual gradation of the snow hardness and by the size of the tip of the SMP. The tip of the SMP is $5 \mathrm{~mm}$ in diameter and about $5 \mathrm{~mm}$ long, and the upper third of the tip has about two-thirds of the surface area. For these profiles we defined the top of the layer as the location where the baseline of the signal stopped dropping and became consistent, 
Table 1. Results from measurements with the QLCT $(n=50$ for 9 Fanuary and $n=48$ for 15 January 2002)
Variable

9 January 200215 January 2002

Mean shear strength index $\left(\mathrm{N} \mathrm{m}^{-2}\right)$

Coefficient of variation strength
Mean shear stress $\left(\mathrm{N} \mathrm{m}^{-2}\right)$

Notes: Shear stress results, calculated from the slope angle, slab density and slab thickness, are based on five measurements for each day. Results are expressed as the mean \pm the standard deviation.

while the bottom of the layer was where the baseline of the signal began to increase again (Fig. 1). This helped assure that the probe tip was within the weak layer for the distance we defined as the surface-hoar layer thickness and that our statistical measures reflected what was happening within the layer. In spite of the complications involved, for most profiles the manual delineation of the weak layer was relatively straightforward.

We then used Interactive Data Language (IDL) data analysis software (RSI, 1998) to calculate the layer thickness and a variety of statistical measures for the force signal for each profile. Since the average weak-layer thickness was about $8 \mathrm{~mm}$, the statistics for the weak layer of an average profile were based on about 2000 force measurements. From these force measurements we calculated a variety of statistical measures for each profile including parametric and non-parametric measures for central tendency and spread (mean, median, minimum, maximum and a variety of quartile measures) and for measures of dispersion (standard deviation, the semi-interquartile range and the quartile coefficient of variation). Since our goal was to compare these statistical measures between the two days, we tested each day's data for normality. Most variables did not pass the Lilliefors test for normality, so we used the non-parametric Mann-Whitney U test to compare the two days (Statsoft, 1994).

To test the effect of small inconsistencies in our manual delineation procedure for the layer identification, we took the delineated layers and added $5 \%$ of the total layer thickness to each boundary to form a hypothetical thicker layer. We also subtracted $5 \%$ of the layer thickness from our original boundaries to form a hypothetical thinner layer. We then ran our statistical analyses on our manually delineated layer, and on the thicker and thinner layers, and compared results to make sure that small differences in the manual delineation of the layer would not affect our results. We tested the significance of the differences with the Mann-Whitney U test.

\section{RESULTS AND DISGUSSION}

Measurements with the QLCT demonstrated a significant $\left(p<10^{-4}\right)$ increase in the shear strength index from 375 to $523 \mathrm{~N} \mathrm{~m}^{-2}$, and slightly increasing shear stress (from 148 to $170 \mathrm{~N} \mathrm{~m}^{-2}$ ) between the two days and the two parts of the slope (Table 1; Fig. 2). Landry (2002) notes that these two sampling days provided the most consistent QLCT results observed in a 2 year study of slope-scale spatial variability in a variety of locations, with coefficients of variation of about 10\%. See Birkeland and Landry (2002) and Landry
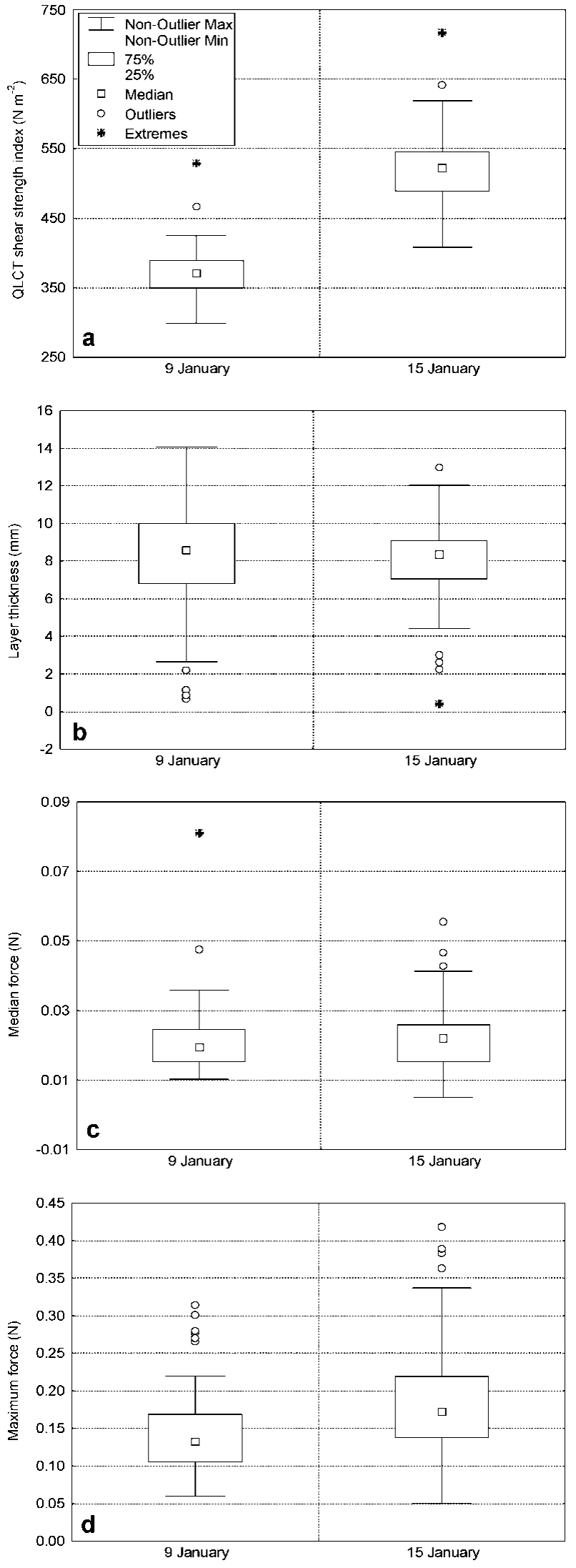

Fig. 2. Box plots of selected variables showing the changes in (a) OLCT shear strength index, (b) layer thickness, (c) median of the SMP signal, and (d) the maximum of the SMP signal between 9 and 15 January. The thickness and the median signal do not statistically differ between the two days, while the shear strength index and the maximum signal increased. Outliers are $>1.5$ times the interquartile range (height of the box) away from the edge of the box, and the extreme values are $>3$ times the interquartile range away from the edge of the box. 
Table 2. Results from SMP measurements ( $n=86$ on 9 January; $n=129$ on 15 fanuary)

Variable

Weak-layer thickness $(\mathrm{mm})$

Mean resistance $(\mathrm{N})$

Standard deviation $(\mathcal{N})$

Coefficient of variation

10 th percentile $(\mathrm{N})$

20 th percentile $(\mathrm{N})$

25th percentile $(\mathrm{N})$

Median resistance $(\mathrm{N})$

75 th percentile $(\mathrm{N})$

80th percentile $(\mathrm{N})$

90th percentile $(\mathcal{N})$

Maximum resistance $(\mathcal{N})$

Semi-interquartile range $(\mathrm{N})$

Quartile coefficient of variation
Minimum resistance $(\mathrm{N})$

9 January 200215 January 2002 p value

$\begin{array}{ccl}8.08 \pm 2.76 & 8.11 \pm 1.91 & 0.58 \\ 0.026 \pm 0.010 & 0.028 \pm 0.010 & 0.21 \\ 0.021 \pm 0.006 & 0.024 \pm 0.008 & <10^{-4} \\ 0.82 \pm 0.21 & 0.92 \pm 0.26 & 0.007 \\ -0.008 \pm 0.007 & -0.010 \pm 0.007 & 0.4 \\ 0.007 \pm 0.007 & 0.006 \pm 0.006 & 0.81 \\ 0.011 \pm 0.008 & 0.010 \pm 0.006 & 0.95 \\ 0.013 \pm 0.008 & 0.012 \pm 0.007 & 0.98 \\ 0.021 \pm 0.010 & 0.021 \pm 0.009 & 0.64 \\ 0.034 \pm 0.013 & 0.035 \pm 0.013 & 0.39 \\ 0.038 \pm 0.013 & 0.040 \pm 0.014 & 0.28 \\ 0.051 \pm 0.017 & 0.056 \pm 0.019 & 0.048 \\ 0.145 \pm 0.055 & 0.182 \pm 0.069 & <10^{-4} \\ 0.010 \pm 0.004 & 0.011 \pm 0.004 & 0.055 \\ 0.466 \pm 0.112 & 0.507 \pm 0.150 & 0.16\end{array}$

Notes: The $p$ values reported are from the Mann-Whitney U test, and variables that increased significantly $(p<0.05)$ are shown in italics. Results are expressed as the mean \pm the standard deviation.

(2002) for a more complete discussion of these data. Though in this paper we correlate some changes in the QLCT shear strength index to the SMP signal within the weak layer, the two tests are quite different. The QLCT is a test whereby a vertical load is rapidly applied to an isolated column until the weak layer fails, and each test covers approximately $8 \times 10^{-2} \mathrm{~m}^{2}$ (Landry and others, 2001). This is more than three orders of magnitude larger than the area covered by a single SMP penetration test, which covers about $2 \times 10^{-5}$ $\mathrm{m}^{2}$ as the probe is inserted perpendicular to the snowpack.

Our manual snow-pit measurements are consistent with a strengthening surface-hoar layer. On 9 January 2002 the maximum crystal size in the layer was $15 \mathrm{~mm}$, while on 15 January the maximum size was $10 \mathrm{~mm}$. We measured the thickness of the surface-hoar layer at only one point in the snow pit and rounded it to the nearest $\mathrm{cm}$. Thickness decreased from $2 \mathrm{~cm}$ on the first day to $1 \mathrm{~cm}$ on the second day. Even though these data are from two points about $100 \mathrm{~m}$ apart, the decreases in maximum crystal size and the thinning of the layer are consistent with other observations of surface-hoar strengthening (Jamieson and Schweizer, 2000). We do not have continuous snowpack temperature measurements, but air temperatures remained cold between the two sampling days, which should have resulted in reasonably strong temperature gradients through the layer and thereby inhibited sintering between the surface hoar and the adjacent layers. The temperature gradient through the surface-hoar layer was $8^{\circ} \mathrm{Cm}^{-1}$ on 9 January and $16^{\circ} \mathrm{C} \mathrm{m}^{-1}$ on 15 January.

The SMP data provide interesting results. First, in contrast to our limited manual measurements, the larger number of spatially distributed SMP measurements showed weak-layer thickness did not significantly change between the two days and sites $(p=0.58)$, remaining roughly constant at about $8 \mathrm{~mm}$ (Table 2; Fig. 2). The variance of the thickness decreased between the two days. This is consistent with, but at an entirely different scale than, results reported by Davis and others (1998) for thin-section measurements of surface-hoar layers. There is no discernible linear spatial trend in the data for either day; a multiple regression analysis using layer thickness as the dependent variable and the $x$ and $y$ coordinates as the independent variables resulted in coefficients of determination less than 0.07 . Our results appear to contradict the conceptual model for surface-hoar strengthening through weak-layer thinning, as well as research investigating strength changes in surfacehoar layers that have correlated weak-layer thinning with increasing strength (Jamieson and Schweizer, 2000). However, our research is much more limited and involves two different parts of the same slope. Though we chose the research site for consistency, and the lack of a linear spatial trend for each day suggests a relatively consistent weak-layer thickness across the slope, it is possible that our two sampling areas started with weak layers of differing thickness. Further, we collected our datasets only 6 days apart, the slab was relatively thin (about $25 \mathrm{~cm}$ ), and little additional load was added to the snowpack between the two days. Even given these limitations, it is interesting that our data demonstrate sizable weak-layer strengthening associated with no, or perhaps only limited, weak-layer thinning.

Another interesting finding is that there is no statistical difference in the mean or median of the SMP force signal within the weak layer between the two days and the two sampling areas (Table 2; Fig. 2). Further, all of the percentile measurements up to the 90th percentile do not significantly differ. The $p$ values of the percentiles consistently decrease with increasing percentile (Table 2). A similar minimum value is expected since much of the SMP signal on both days through the weak layer is within either extremely weak snow or pore space (Fig. lb and c). The small negative values observed for the minimum force measurements are a result of the offset of the SMP, which is calculated as the mean of the SMP signal in the air, thereby leading to some small negative values in the air, or in the voids of our surface-hoar layer. Though similar minimum measurements for the two days make sense, in a strengthening weak layer we might anticipate an increase in the mean or median of the force signal. There must be more important measures that quantify changes in the strength of buried surface-hoar layers.

The values that do statistically differ $(p<0.05)$ between the first and second day are the variance, coefficient of variation and 90th percentile measurement of the SMP signal, and maximum penetration resistance within the weak layer (Table 2; Fig. 2). All of these parameters increase between the two days. Not surprisingly, the variance and maximum signal are highly correlated on both days (Spearman $r>0.83$ ), indicating that our high variance measures are occurring at locations with a high maximum. Our results suggest that a key value of the SMP force signal within a buried surface-hoar layer may be the maximum penetration resistance, or perhaps the variance of the signal. Since there are relatively few bonds between a surface-hoar layer and the adjacent layers, perhaps only one or a couple of these bonds are ruptured as the small SMP tip passes through the layer. We hypothesize that the breaking of the most significant bond encountered by the SMP tip may give the maximum signal, while smaller signal spikes may be due to other bonds being broken or crystals getting pushed aside (Fig. 1c). Thus, the maximum signal may give us the best indication of how the bonds and the layer are strengthening. Subsequently, we tried to discern the part of the weak layer (upper, middle or lower) most commonly associated with the maximum signal, but our analyses indicated that 
the maximum SMP signal could occur at any level. We believe this is because the small tip can interact with the widely spaced surface-hoar crystals in any part of the layer.

We compared the statistics for our manually delineated layers with the statistics for the layer plus $5 \%$ of the layer thickness on each side and minus $5 \%$ of the layer on each side. For both days, and for all our statistical measures, we found no statistically significant differences (all $p>0.20$ and most $p>0.50$ ) between our manually delineated layer and either the thicker or thinner layer. This demonstrates that our manual delineation technique is reasonably robust for these data; small differences in how the layer boundaries are delineated do not affect our results.

\section{SUMMARY}

The shear strength index associated with a buried surfacehoar layer increased between 9 and 15 January 2002 at our two sites (Table 1; Fig. 2), and our SMP measurements also show changes in the SMP signal. Perhaps somewhat surprisingly, layer thickness, as well as the mean, median, minimum and most percentile measurements of the penetration resistance within the weak layer, did not change significantly (Table 2; Fig. 2). However, the variance, coefficient of variation, 90th percentile and the maximum signal all increased between the two days and sites (Table 2; Fig. 2). Though we cannot provide a direct link between QLCT results and SMP measurements, our results suggest that the maximum penetration resistance might be important for predicting changes in shear strength. This may be because the SMP is breaking relatively few bonds within the weak layer, but those few bonds that it does break have become stronger.

The data for this research came from two parts of the same slope located about $45 \mathrm{~m}$ apart. Thus, we cannot be sure whether the changes we measured are temporal or spatial, or a combination of both. This is always a problem with field studies of snow, a highly spatially variable material which is also typically destroyed at a specific location during the sampling process. In our case, neither of the two parts of the slope we tested displayed linear spatial trends in any of our primary variables such as weak-layer thickness, mean penetration resistance or maximum penetration resistance. The lack of such trends on two closely related parts of the same slope suggests relatively uniform conditions across the slope. Though not absolutely conclusive, this provides evidence that the trends we observed were primarily temporal changes rather than spatial changes.

Our results have implications for how we view weak layers and bond strength. To interpret the SMP signal, we cannot simply think of a weak layer as being homogeneous; instead, we need to visualize a more complex weak layer with a corresponding distribution of bond strengths. Our data show that the center of the distribution of the penetration resistance measurements within our surface-hoar layer (as measured by the mean and median) did not change between the two days. However, our maximum signal increased, demonstrating that the strongest bonds in the layer have become stronger between the two sampling days at our two sites.

Clearly, our work is only a first step toward quantifying the changes in the SMP signal within a strengthening weak layer. Further research is needed to more definitively corre- late changes in the SMP signal within buried surface-hoar layers, and other weak layers, to changing shear strength, stability and avalanche conditions on specific slopes.

\section{ACKNOWLEDGEMENTS}

We are grateful to C. Landry, who helped coordinate field days, provided field data and engaged in useful discussions about this work. Montana State University TechLink funded the purchase of the SMP. Special thanks go to B. Brown, D. Chabot, J. Deems, R. Johnson, D. Miller and M. Cooperstein for their great help in the field. B. Jamieson (editor) and two anonymous reviewers provided constructive criticism that greatly improved this paper. This work was supported in part by the U.S. National Science Foundation (BCS-0240310) and the Swiss National Science Foundation (2000-066643.01).

\section{REFERENGES}

Birkeland, K.W. and C. C. Landry. 2002. Changes in spatial patterns of snow stability through time. In Stevens, J. R., ed. International Snow Science Workshop 2002, 29 September-4 October 2002, Pentiction, British Columbia. Proceedings. Victoria, B.C., B.C. Ministry of Transportation. Snow Avalanche Programs, 482-490. (http://www.fsavalanche.org/NAC/ techPages/articles/02_ISSW spatial_var_time.pdf.)

Chalmers, T. S. and J. B. Jamieson. 2001. Extrapolating the skier stability of buried surface-hoar layers from study plot measurements. Cold Reg. Sci. Technol., 33(2-3), 163-177.

Chalmers, T. S. and J. B. Jamieson. 2003. A snow-profile-based forecasting model for skier-triggered avalanches on surface-hoar layers in the Columbia Mountains of Canada. Cold Reg. Sci. Technol., 37(3), 373-389.

Colbeck, S. C. and 7 others. 1990. The international classification for seasonal snow on the ground. Wallingford, Oxfordshire, International Association of Scientific Hydrology. International Commission on Snow and Ice.

Davis, R. E., B. Jamieson, J. Hughes and C. Johnston. 1997. Observations on buried surface hoar - persistent failure planes for slab avalanches in British Columbia, Canada. In ISSW'96. International Snow Science Workshop, 6-10 October 1996, Banff, Alberta. Proceedings. Revelstoke, B.C., Canadian Avalanche Association, 81-85.

Davis, R. E., B. Jamieson and C. D. Johnston. 1998. Observations on buried surface hoar in British Columbia, Canada - section plane analysis of layer evolution. In ISSW'98. International Snow Science Workshop, 27 September-1 October 1998, Sunriver, Oregon. Proceedings. Seattle, WA, Washington State Department of Transportation, 86-92.

Hachikubo, A. and E. Akitaya. 1997. Effect of wind on surface-hoar growth on snow. 7. Geophys. Res., 102(D4), 4367-4373.

Jamieson, J. B. 1995. Avalanche prediction for persistent snow slabs. (Ph.D. thesis, University of Calgary.)

Jamieson, J. B. and C.D. Johnston. 1999. Snowpack factors associated with strength changes of buried surface-hoar layers. Cold Reg. Sci. Technol., 30(1-3), 19-34.

Jamieson, J. B. and J. Schweizer. 2000. Texture and strength changes of buried surface-hoar layers with implications for dry snow-slab avalanche release. F. Glaciol., 46(152), 151-160.

Johnson, J. B. and M. Schneebeli. 1999. Characterizing the microstructural and micromechanical properties of snow. Cold Reg. Sci. Technol., 30(1-3), 91- 100 .

Landry, C. C. 2002. Spatial variation in snow stability on uniform slopes: implications for extrapolation to surrounding terrain. (M.Sc. thesis, Montana State University.) (http://www.fsavalanche.org/NAC/techPages/theses/landry.pdf.)

Landry, C. C., J. Borkowski and R. L. Brown. 2001. Quantified loaded column stability test: mechanics, procedure, sample-size selection, and trials. Cold Reg. Sci. Technol., 33(2-3), 103-121.

Landry, C. C., K. W. Birkeland, K. Hansen, J. Borkowski, R. L. Brown and R. Aspinall. 2002. Snow stability on uniform slopes: implications for avalanche forecasting. In Stevens, J. R., ed. International Snow Science Workshop 2002, 29 September-4 October 2002, Pentiction, British Columbia. Proceedings. Victoria, B.C., B.C. Ministry of Transportation. Snow Avalanche Programs, 532-539. (http://www.fsavalanche.org/NAC/ techPages/articles/02.ISSW-Landry.pdf.) 
Lang, R. M., B. R. Leo and R. L. Brown. 1984. Observations on the growth process and strength characteristics of surface hoar. In ISSW' 84 . A merging of theory and practice. International Snow Science Workshop, 24-27 October 1984, Aspen, Colorado. Proceedings. Aspen, CO, ISSW Workshop Committee, 188-195.

Pielmeier, C. and M. Schneebeli. In press. Snow stratigraphy measured by snow hardness and compared to surface section images. Cold Reg. Sci. Technol.

Pielmeier, C., M. Schneebeli and T. Stucki. 2001. Snow texture: a comparison of empirical versus simulated texture index for Alpine snow. Ann. Glaciol., 32, 7-13.
Research Systems Inc. (RSI). 1998. IDL reference guides. Vols. I and II. Boulder, CO, Research Systems Inc.

Schneebeli, M. 1999. High resolution penetrometry in the high-porosity material snow. In International Workshop on Penetrometry in the Solar System. Proceedings. Vienna, Verlag der Österreichischen Akademie der Wissenschaften Wien, 61-72.

Schneebeli, M., C. Pielmeier and J. B. Johnson. 1999. Measuring snow microstructure and hardness using a high resolution penetrometer. Cold Reg. Sci. Technol., 30(1-3), 101-114.

Statsoft. 1994. Statistica Volume I: general conventions and statistics I. Tulsa, OK, Statsoft. 